\title{
Photographic Image: Thematization of Its Discourses
}

\author{
Ricardo Crisafulli Rodrigues
}

Department of Organization, Instituto Brasileiro de Informação em Ciência e Tecnologia (IBICT, Brazilian Institute for Information in Science and Technology), Brasília, Brasil.

Email: ricardo@ibict.br

Received September $18^{\text {th }}, 2013$; revised October $20^{\text {th }}, 2013$; accepted October $28^{\text {th }}, 2013$

Copyright (C) 2013 Ricardo Crisafulli Rodrigues. This is an open access article distributed under the Creative Commons Attribution License, which permits unrestricted use, distribution, and reproduction in any medium, provided the original work is properly cited.

\begin{abstract}
This paper deals with thematization as a fundamental step towards the determination of photography image discourses in order to index them. It deals with questions related to photographic reality, polysemy, denotation and connotation, whose comprehension is fundamentally important for the interpretation of photography discourses. It also approaches aspects that have influenced photography analysis towards its thematization, such as the characterization of an image bank, the functions performed by photos, as well as technical and visual quality.
\end{abstract}

Keywords: Descriptive Analysis; Interpretative Analysis; Photographic Connotation; Photographic Denotation; Imagetic Discourses; Thematic Discourses; Photography; Image; Photographic Image; Polysemy of Photographic Image; Photographic Referent; Thematization; Thematization of Photographic Image; Thematization and Indexing

\section{Introduction}

Many image information systems do not satisfactorily perform the administration of the photographs that will become part of their collections; this generates photographic collections that are inadequate and/or not pertinent. In general, the works of photo identification and its denotative description are not done properly, as they give more emphasis to its purely visual aspect. In most cases, when the connotative interpretation of its context is done, one does not delimit or direct the thematic discourses that photography might possess and, when one does it, the work is almost always disassociated from the objectives and characteristics of the image bank.

In most of that work done, there is no concern with two factors related to photographic image: the time of selection/acquisition and the time of thematization, as well as its visual and technical qualities - both highly relevant to the user and without which, photography might lose much of its informative potential.

Consequently, the user mostly often has to perform searches in more than one image bank, using as parameters not only the theme of one's research object, but several related themes within which one expects to find what is searched. Subsequently, in many cases when one finds the material searched, it does not hold the adequate dis- courses or it lacks technical and visual qualities that enable its use. Generally, these failures are the result of the inexistence of technical tools to assist the work developed by professionals in many image banks, in the selection/acquisition, analysis, thematization, indexation, storage and retrieval of photos.

The image, in its various supports and techniques, has always been one of the main mechanisms of communication in the history of humanity. Nowadays, thanks to photography, it has been highlighted, especially with the advent of the Internet and global communication due to hypermedia, which is the combination of information into multiple dimensions: text, image, audio [1].

The invention of photography during the Industrial Revolution allowed a gradual expansion in the production and use of images, firstly, in a more selective and almost individual way and, subsequently, in a more massive way such as illustrating newspapers, magazines, advertising media, technical-scientific documents, among others. Later, it forsakes being just art and individual memory to become information and knowledge; therefore, it started being produced and disseminated by various media, mainly as textual information support.

However, no matter how hard one tries to create a specific photographic image - in relation to its context and expression - to convey information and a determined 
knowledge, there will always be innumerous interpretations. This is due to the diverse socio-cultural levels and experience of each person's life, i.e., one's cognition and mental image. The photographic image-like all forms of images - is, therefore, polysemic or ambiguous, for it allows several different discourses that need to be explained a priori by the bank of images, allowing their recovery, whenever necessary, by the different types of users.

Two senses are part of a photo as to its content: the denotative and connotative meaning. In the denotative one, there is little room for interpretations. What the receptor sees and assimilates is a literal, objective and practical copy and, most often, faithful to a particular referent. If it depicts a destroyed bridge over a river, it will be seen by everyone as it was registered, even if its original color, for example, has been modified by the photographer or a photo editor. The bridge will still be seen as a bridge in a state of destruction. The river will be seen as just a river. If there is a person there, the person will be seen only as a person. In this sense, the photo just says that it is about something; that it refers simply to something; that it indicates the existence of something without explaining what that thing is.

Such photo, however, may be about something, having multiple meanings and allowing for innumerous interpretations by different people, which leads to different thematized discourses. Some may interpret the scene of the collapsed bridge as a result of an earthquake; others, as a result of a bombing in a war, and so on. Different interpretations add a connotative sense to image, allowing for the establishment of discourses and senses loaded with various values.

In information service, or in an image bank that is supposed to supply information through images to researches or other ends, the concrete and abstract connotative senses have to be contextualized a priori by the specialists who organize the photos. The contextualization of these connotative senses, known as thematization, will open up possibilities for photo use in different topics and subjects, different interpretations and ends by directing and restricting the scope of its thematic discourses.

Thematization has also contributed to the selection of photos that are compatible with the characteristics and objectives of the image banks, mainly the specialized ones. Thematization is, therefore, a technique that antecedes photographic image indexation by directing the discourses within it. By delimiting discourses, in a certain way, it determines the photography's themes that interest the image banks. Thus, it establishes the limits in which the photo will be indexed and for which there will be metadata in terms of recovery.

The present paper deals with photographic image thematization from a generic concept of thematization. It shows how_-based on polysemy-diverse discourses can be found in photography and how denotative and connotative thematization can determine and make those discourses visible.

It also approaches image thematization in the history of humanity as something that has been done according to the interests and necessities of domination of a social or religious class upon society in general.

Technically, the text emphasizes the differences between thematization and indexation; it also discusses many factors that influence thematization and photography discourse determination $[2,3]$.

\section{The Photographic Image}

The large amount of photos that has been produced so far led to the creation of innumerous image banks; some highly professional while others quite amateurish with almost no technical or qualitative resources. All that "imagetic mass", however, needs an adequate organization that allows its fast and efficient retrieval by the ones who need them. This organization involves a series of activeties, including those in which thematization allows for the determination, delimitation and direction of photography discourses.

Nevertheless, before talking about those subjects, it is necessary to understand some aspects linked to photography theories, such as: photography reality, photography referent, denotation, concrete and abstract connotation, polysemy, among others.

\subsection{Photography Reality and Photography Referent}

Any photo, regardless of the function it performs, brings an air of reality, i.e., of something that exists or existed; of something that is or was; of something genuine or real. This presumed reality is mainly due to photography's technical nature that reproduces, in a mechanically and apparently unambiguous way, a real scene framed by a camera that is later chemically or electronically printed in a light-sensitive surface. Unlike painting, drawing, sculpture and other forms of imagery representation that arise from a creative craft and manual labor of an artist, photography (as well as cinema and television) requires a mechanical device - a camera - in order to exist. This device, at first, allows for an apparently true recording of an object (referent) just as it presents itself to the photographer's eye, hence causing the feeling of reality and truth in relation to the fact or object photographed.

According to Sontag [4], the photos are, in some way, "true" and furnish some kind of evidence.

Something we hear about, but doubt, seems proven when we're shown a photograph of it [ $\cdots]$ A photograph passes for incontrovertible proof that a given thing hap- 
pened. The picture may distort; but there is always a presumption that something exists, or did exist, which is like what is in the picture. Whatever the limitations (through amateurism) or pretensions (through artistry) of the individual photographer, a photograph - any photograph - seems to have a more innocent, and therefore more accurate, relation to visible reality than do other mimetic objects.

According to Kossoy [5], the reality depicted is a "second reality", being the "first reality" the object or topic itself depicted (referent). Dubois, in his book The photographic act and other essays [6] suggests, based on "positions advocated by critics and photography theorists", three distinct periods in photography understanding in relation to its reality and its referent, which he called: 1) photography as a mirror of reality; 2) photography as a transformation of reality; and 3) photography as a trace of reality.

The notion of photography as a mirror of reality occurred in the 19th Century - a period in which photography was considered "the most perfect imitation of reality"-and this was the first discourse on the topic. This view placed photography as a faithful reproduction of reality, "the world's mirror".

The notion of photography as a transformation of reality appeared in the 20th Century from observations of photography failures in relation to "its supposedly perfect representation of the real world" [6].

According to the conception of photography as a transformation of reality, on creating an image, the photographer defines what he wants to show, i.e., what fraction of reality will be seen, in which position, under what light, with which colors, in what distance, with what conflicting or compatible elements, with what type of lens, under what point of view ${ }^{1}$ etc. These variables have led photography scholars to state that photography is not a mirror of reality, but reality transformed and interpreted according to the vision of whoever produced it.

Photography as a trace of reality is, somehow, an adjustment or a consensus between the two first theories. For those who adopt this theory, photography is not separate from its "first reality" which is always present through its referent that exists or existed. In this case, it is an undisputed proof of something that took place in a specific time, in a specific place and in a specific manner. The referent's mark is present in the image, although it might seem to be an abstract object. However, this referent's sense and meaning is in the personal interpretation

\footnotetext{
${ }^{1}$ Point of view, in this case, refers to the photographer and the camera's physical position in relation to the object or scene to be photographed. If the photographer captures a scene from a point below it, it is said that it was captured from an inferior point of view. If his/her position were above the scene, it is Said that is was captured from a superior point of view. The resulting photo is significantly altered according to the difference in the point of view.
}

of the one who sees the photo, and according one's mental image and cognition. According to [6], a photograph is first of all an index of something that once took place in a specific time, then an icon of that specific event, and eventually a symbol filtered through subjective perception.

Whatever interpretations and positions adopted by scholars, the "first reality" of the photographic image is always linked to a referent, i.e., to something that exists or physically existed. An image's referent is a real object preexisting in that image, something concrete or conceptual that served as model or inspired its elaboration. In photographic image - however abstract it might be - the referent is, necessarily, real and concrete.

\subsection{Polysemy, Denotation and Connotation}

Polysemy (poli = many and semy = meanings). In a wider context, it refers to something that can hold various meanings according to the different contexts in which it is inserted.

In photography, polysemy refers to the diverse interpretations the same photo may hold, depending on the context in which it is inserted, on the function it performs and on the user's mental image and cognition.

Polysemy is basically caused in photography by the differences in people's perception and interpretation capacities. Each one perceives and interprets an image according to one's visual system's reactions and peculiarities, one's mental images, cognition, culture and education.

Taking the theory photography as a trace of reality, we can find two different meanings in photography that are linked to its polysemy: 1) denotation that directly refers to the "first reality" in which its referent is situated in the perception domain; and 2) connotation that directly refers to the "second reality" and is situated in the interpretation domain. The denotative domain refers to that which the image represents with "certain accuracy", in its real meaning; the connotative one refers to that which can be "interpreted" in a specific context, in a figurative and symbolic sense. In the denotative sense there is no room for interpretations. What the receptor sees is similar to a literal, objective and practical copy, and it is mostly faithful to a specific referent. The different interpretations give, nevertheless, an abstract and concrete connotative sense to image since it is exposed to other contexts that give it new senses loaded with distinct values. Shatford [7] addresses the issues of photography senses adopting the terminologies OF and ABOUT. For her, the "OF" indicates what photography is made OF and refers to the denotative sense. The "ABOUT" indicates "that which the photo is ABOUT" and is associated to the connotative sense (concrete and abstract). A photo 
can be, for instance, OF a child crying and also ABOUT starving, abandoned, children; children's sickness, dread, unhappiness, pain and many other interpretations made by those who see the photo.

\section{Thematization}

The word thematization is not easily found in dictionaries, in dictionaries in Portuguese, English, Spanish, French, Italian, German, etc. However, the term may be associated to the word theme, whose meaning is a proposition that will be dealt with or demonstrated. In this case, the word thematize (which does not exist as a verb) can be adopted as a verb in the sense of creating or selecting a theme (topic) to something ${ }^{2}$ and, as a noun, thematization, means the act of effect of thematizing.

Despite the "official" inexistence of the word, but based on the meanings brought to life from the entry theme, we can conceptually understand thematization as an act or action of giving one or more topics or (specific) meanings to an object or thing.

In this context, many fields of knowledge and human activity can receive thematizing actions that may be susceptibly put into a frame in two great groups:

In the first, the possible concrete or abstract themes that might be comprised into a determined thing (texts, images in general, photographs, and diverse objects, sounds, etc) can be identified through the interpretative analysis. In this first group, photographic image is perfectly fitted. Figure 1, for example, may include, among others, the following concrete and abstract themes, taking into consideration its "visible" and "invisible" characteristics.

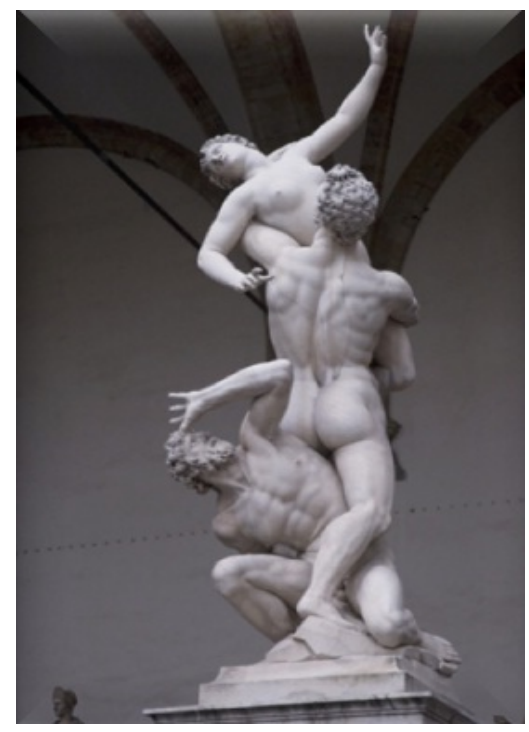

Concrete themes: violence, aggression, kidnapping, Roman mythology, Roman History. Abstract themes: fear, dread, force, domination.

Figure 1. The rape of the Sabine women/Photo Ricardo Rodrigues.
In the second group, one might search, from the choice of a particular theme, objects and various concepts that assembled represent that theme. Figure 2, for instance, shows a medieval-themed hotel and all the segments below favor the creation of the theme related to the hotel.

Thematic segments associated to the hotel: hotel construction and decoration in medieval style; typical medieval food offered by the hotel; costumes worn by hotel staff; typical medieval feasts promoted by the hotel; library books of medieval subjects open to guests; medieval music played during leisure activities and as background music.

In general, any thing devoid of a context has no discourse that gives it a practical and real meaning. This meaning, among other ways, can also be created through thematization that, besides enabling the visualization of the discourses explicitly pertinent to the thing, can change it in part or completely, influencing how people perceive and assimilate this thing. The same concept of object may appear in different thematic discourses causing diverse senses that are influenced by the characteristics of whoever produced the thematization and whoever used it.

The discourses produced by thematization allow interaction between the individuals who produced them and those who share some intimacy with the thing thematized. By producing the thematization discourse, the individual creates meaning that is influenced in part by one's culture, ideologies, social position, cognition and mental image. These characteristics must be in accordance with the characteristics of those to whom the discourse is addressed, otherwise, there will be no possibility of communication between producer and user and the thematization will result innocuous. Whoever creates a thematization discourse seeks to persuade that one who absorbs this discourse; hence the great importance that the characteristics of both be compatible.

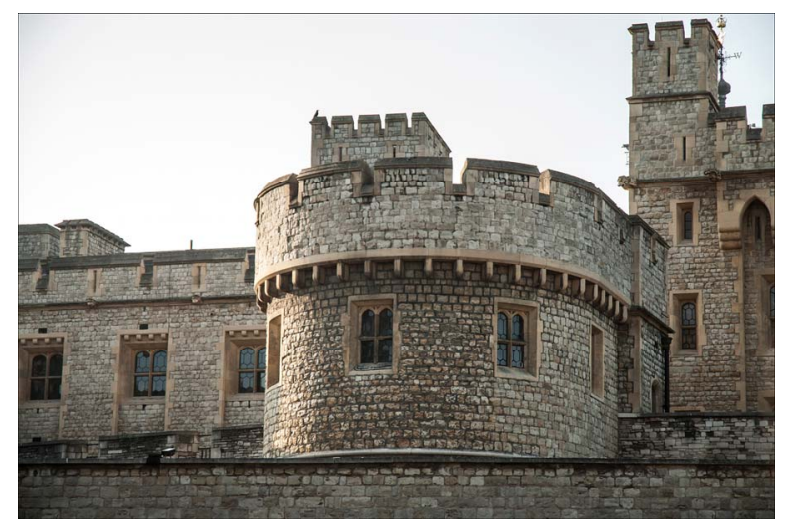

Figure 2. Example of a medieval themed hotel.

${ }^{2}$ Something, according to dictionaries, is understood as "all that exists ou can exist, entity, object [ $\cdots]$ that what is thought of" [8]. "Occurrence, event, circumstance. Fact, reality. Subject, matter or object which is dealt about" [9]. 
In its evolution, humanity has always brought within itself the primitive domination of some men upon others, and image has played an important role in this domain, due to the thematized discourses in which it was created and/or used. Throughout time, those who have governed ${ }^{3}$ - and who govern-have always used thematized discourses in their many forms (painting, sculpture, drawing, photography, cinema, TV, etc.) to direct people by forcing them, in a certain way, to accept their ideas, feelings and ideologies. Each image produced or used by these governors with the purpose of domination brings with it a thematized discourse that determines and directs its polysemic characteristic.

In every moment throughout History, image has allowed the most diverse thematization. Much was readily perceived, since images were almost always handmade and individually created in order to meet determined themes. The invention of photography and its great expansion especially after the advent of digital photography, in part changed the way one views the image. Created from an object/existing living thing-what allows for different interpretations and points of view-photography significantly expands the interpretative possibilities, making it much more polysemic than the other types of image. However, when thematizing a photograph taking into account its objective and function, besides the characteristics of the image bank where it will be inserted, it becomes possible to identify and direct potential themes that might arise. Such procedure allows for greater rationalization in indexing, besides the possibility of inserting determined photographs on topics in which, apparently, would not be inserted since they do not belong directly to them.

Thematizing a photographic image means a priori ${ }^{4}$ to contextualize its connotative senses, allowing for its being used in different topics and subjects, for different interpretations and purposes, directing and delimiting the scope of its thematic discourse.

The use of thematization is justified by the large amount of photographic images produced daily worldwide, significantly hindering their organization and retrieval.

In the words of Smit [10] "the description of an image is never complete" and Manini [11] adds: "there will always be something to wonder about it", increasing the difficulty in recognizing what to index and to what depth. The use of an adequate thematization can, however, define and direct the image discourse establishing limits to its polysemy, besides allowing the incorporation of themes apparently out of the context. It also contributes to choosing, at the moment of indexing, only those photos that are compatible, that share the characteristics and objec-

\footnotetext{
${ }^{3}$ Kings, churches, governments, intellectuals, professors, communication and advertizing media, etc.

${ }^{4} A$ priori means the actualization of thematization before the use of the image by the user.
}

tives of the image banks, mainly those of specialized nature. Thematization is, therefore, a technique that antecedes photographic image indexation by delimiting and directing its discourse.

By delimiting discourses, thematization, somehow, selects the photographs' themes that interest the image banks. It establishes the limits into which the photo will be indexed and for which it will have metadata and retrieval terms. A photo, for instance, can comprise various discourses A, B, C, D, E, F, G, H etc. From these, just B, $\mathrm{D}, \mathrm{E}$ and $\mathrm{H}$ discourses are interesting for the image bank. In this case, the photo will be interpreted and subsequently indexed according to those themes' discourses. The other discourses, although present in the photo, will not be considered since they are of no interest to the image bank (Figure 3).

The chosen discourses can hold concrete connotative (B e H) and abstract connotative senses (D e E) that, when delimited, direct the photo by connecting it to other photos' similar discourses that are already part of the image bank. Mainly the abstract connotative ones, which are not clearly implicit in the images, allow for a management that enlarges the possibilities of the photo's use (Figure 4).

For a good work of thematization, however, an accurate analysis of the photographic image becomes necessary; an analysis that will, in a certain way, also consider the necessities of the acquisition/selection and indexation process. Therefore, it is possible to analyze a photograph for all those tasks in just a moment.

Nowadays, the necessity of image organization and retrieval has significantly grown especially with the enormous proliferation of mainly digital photos, causing the emergence of innumerous image banks whose thousands of images need to be accessible to users. In broader terms, those banks have adopted a notion close to those defined by several authors for whom the photographic analysis aims at orally identifying the informational content of the photograph. According to Smit [10], "to analyze an image means, whether we like it or not, 'to translate' certain

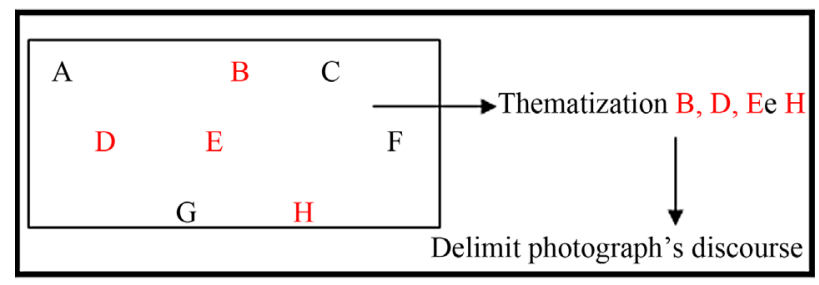

Figure 3. Delimit photograph's discourse.

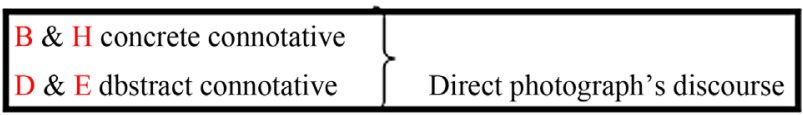

Figure 4. Direct photograph's discourse. 
elements of that image from an iconic code to a verbal code". Maimone [12] defines: "image analysis is nothing more than translating to a verbal language, the visual aspect of a work, such as, photos, movies, paintings, and so on. In this sense, the image in its content intends to convey meanings, whether explicit or not". According to Brasil [13], analyzing image means identifying and specifying image's characteristics. This is the key to all image indexing systems $[\cdots]$ the purpose of an image retrieval system is to operate on a collection of indexed images, and, in response to a user's request (query), provide relevant images according to established criteria.

\section{Thematization and Indexing}

While for some it may seem that thematization and indexing are the same, there is a difference of purpose between the two techniques, even though both use up the results of the same analyses for a given photographic image. In a process of photo organization, thematization is the first "consequence" of interpretative analysis, preceding indexing, delimiting and directing image polysemy.

Thematization includes determining, beyond the central focus, which other referents or units ${ }^{5}$ within the referents will have their discourses chosen to be indexed and become part of an image bank.

According to Lancaster's concepts [14], thematization can lead to "selective indexing, which implies the use of fewer quantity of terms, in order to cover the thematic content of the document." When counting on the initial aid of thematization, the indexing of photographs - from image bank characteristics and photo functions - is, therefore, situated in the "selective indexing" category that brings a fewer number of terms or key-words, or term descriptors, thou with more objectivity for the retrieval of photos, still according to Lancaster [14].

For whatever specific information need, there will be much more negative items (not relevant to what one seeks) than positive in the searching moment. Positive items would be followed by a great amount of negative ones (emphasis added).

Thematization, when limiting and directing photos' discourses, can retrieve as many images as possible with fewer number of negative items encompassing images that are relevant to users' necessities. Indexing can be, therefore, influenced by thematization's actions performed beforehand.

Indexing photographic image means the activities de-

\footnotetext{
${ }^{5}$ Units are parts of the photo obtained from the image segregation process, i.e. from the identification and separation of image constitutive parts. One or more parts can be segregated, depending on how the image is being perceived or on its analytical needs. In order to segregate a figure in an image, it is necessary that it be distinguished from the others in the surround or that it have a significant content in the photo.
}

veloped with the purpose of determining identifying aspects (key-words, term descriptors, etc.) for previously analyzed photos' topics or subjects. Photos' retrieval quality in an image database is directly related to the quality of indexing. According to Souza [15], "an image retrieval system's objective is to operate on a collection of (indexed) images and, in response to a query, present 'images that are relevant' according to established criteria". Thus, the better the indexing quality, the greater the chances of finding those desired photos.

In a photographic image, after analysis, one can verify the existence of various discourses with differentiated themes that are due to the natural polysemy of this type of document. Indexing can be done in a broadly way in which each of these discourses will be indexed with various key-words or other types of indexes. In this case, there will be a large universe of indexed themes, many of which might not be directly related to the objectives and characteristics of the image bank, the functions to be performed by the photograph, and the field of knowledge in which it will be used or the image bank's target audience. In this case, a "super overvaluation of indexing terms" is shaped, for many of them will be "superfluous" in relation to use, increasing the indexing work efforts and creating a storage of key-words and other types of indexes that will never be used in a specific image bank.

The use of thematization as a technique prior to the selection of indexing terms will allow, in turn, that topics of interest or subjects apparently not related to the photograph in question be restricted to the topic of discussion; thus, they will be grouped with other similar topics and, finally, will direct the photograph just to relevant topics. This will allow less indexing effort, besides a descriptive set of words and key-words more focused on the image bank's characteristics.

\section{Factors Affecting Photographic Image Thematization}

When analyzing a photo, it is necessary to observe the existence of several factors that, to a greater or lenses extent, will determine whether it is going to be part of an image bank. If those factors are not observed, all the photos received by the bank will be incorporated to it, generating a large amount of "trash" in its input and hence, its output. Most of those factors must be observed at the stage of the photos' selection/acquisition. However, other aspects should be observed in the thematization phase, which will lead to the indexing and subsequent incorporation of key-words or term descriptors necessary to the photos' retrieval. Among those factors we detach:

\subsection{Technical Quality}

Technical quality is related to a set of conditions that 
allows a photographic image to be considered suitable for use in different situations and able to communicate imagetic information. It involves the correct use of light, lenses, films/sensors, digital resolution, and sharpness/ depth of field.

Sometimes there is only a photographic record of an event with poor technical quality ${ }^{6}$. In this case, the informational value counts more than any type of qualitative scheme and the photo acquires an aspect of "rarity" or of "opportunity", and it should be incorporated to, albeit for a limited time, the image bank.

\subsection{Visual Quality}

Once the image is denotatively assimilated by the brain, the connotative process starts taking place, and, the more visual qualities exist in the same, the greater the chances of it being connotatively absorbed and interpreted. We understand visual quality as a set of characteristics mainly related to the framing and composition that give the photo, besides a finer look, a framework for greater compatibility between the visual and mental systems. Although established at the time of the photo creation, it is felt basically at the first perception moment, in the sight's physiological dimension, when the indexing or denotative aspect is assimilated by the sight and transferred to the brain, influencing it to understand the image.

The importance of a photo's visual quality is strongly supported by the Gestalt psychology-an experimental school of thought that, among other aspects, significantly acts in the field of the theory of shape, according to Gomes Filho [16].

The Gestalt theory, drawn from rigorous experimentation, will suggest and answer why some images please more while others do not. This way of approaching the issue is opposed to that of subjectivism, for the psychology of shapes is based on the physiology of the nervous system, referring to its search of explaining the subject-object relationship in the field of perception.

\subsection{Photograph's Possible Functions}

In general, in the specialized literature, authors classify photographs according to their types of techniques (there are, inclusive, photographers specialized in those different types and techniques), according to the subjects of topics to be photographed.

However, each of those types can fulfill various roles in knowledge transmission, attributing to photographs different functions, according to the circumstances and

\footnotetext{
${ }^{6}$ It may happen, for instance, that in a plane crash the only photo that recorded the accident was a cell phone's picture with low technical and visual quality. However, since it may be the only existing picture, it will be considered by its informational qualities, rather than any technical or visual quality.
}

moments in which they will be used. In many cases, a certain photograph might have more than one purpose and produce different discourses. A photo of a soccer player running after a ball, for instance, might perform several functions, such as: reporting on a game, showing a moment in the soccer player's life, what sports is about, sports fashion, among others.

\subsection{Image Bank’s Characteristics}

An image bank is defined not as a simple software or a site that provides images, but as an institution's technical service that selects, acquires, organizes, stores, and allows photographic images' retrieval according to the polices and pre-established principles.

The content of a photographic image, thou it might be denotatively described in a similar way by many image banks, allows different connotative interpretations depending on the banks' characteristics, which reads an image discourse in different ways. It is vital, therefore, to understand the objectives and characteristics of an image bank before analyzing a photograph according to its determined thematic discourses, since its objectives and characteristics will interfere in choosing which discourses will be chosen. Generally, six categories of banks are identified:

- library image banks;

- image banks of files and institutions for the preservation and exhibition of images;

- newspapers' image banks;

- magazines' image banks;

- image agencies' image banks;

- news' image banks.

According that type of categorization, requirements of time, pertinence, technical quality, visual quality, denotation, connotation, among others of the analyzed and stored material considerably vary according to the image bank's characteristics.

\section{Thematization and the Determination of Discourses}

As stated earlier in this article, any thing, devoid of a context in which it suits, has no discourse that gives it a practical and real discourse. A photograph, by itself, has no meaning if it is not contextualized, constituting only an image that represents something, a referent that seems to have no meaning. The photo of a screw (Figure 5), for

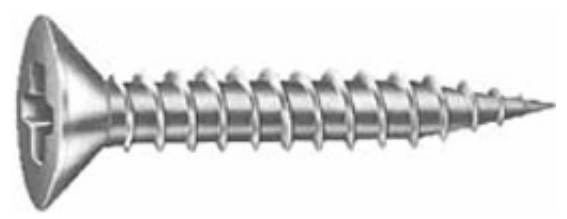

Figure 5. A screw. 
instance, does not mean absolutely anything if there is no context in which it fits. Many times it might not be identified as a screw if the image receptor does not know what a screw is.

To have meaning, the photo of the screw needs to be contextualized with some thematic discourse indicating what it is ABOUT. It might be, for instance, ABOUT "security", since a screw securely holds two or more things; ABOUT "coupling", since it holds two or more things; ABOUT "design", since the drawing of a screw requires some patterned metallurgic specifications; ABOUT "metallurgy", since it is manufactured in this field, etc. By establishing a thematic discourse, the photo of the screw will be embedding itself within a context. This is done a priori in the image bank. However, the photo's discourse will be in a "dormant" state until it is retrieved by one of those themes (security, coupling, design, or metallurgy).

Photographic image thematization belongs to the first set of actions that can be thematized, i.e., a set of things that implicitly bring in their context one or more discourses in a "dormant" state, waiting to be determined a priori by an image bank and received by a receptor. That determination will allow that one delimits and directs the discourses according to the relevant characteristics of the image bank in which it will be inserted, favoring the imagetic information analysts on their posterior photo indexing work. The photo of the screw might carry many of the topics described above. However, if it belongs to, for instance, an image bank specialized in metals, the thematic discourses to be considered are those related to "design" and "metallurgy". The others will be discarded from this image bank. Diagram 1 allows us to view and delimit that direction.

Although not an established norm, thematization activities must obey a logical flow of tasks that might facilitate the determination of the discourses adequate to an image bank. It is assumed that, when beginning that flow, the analyst already knows for sure which image bank's characteristics and types of discourses might or might not be incorporated to it. In the example of the screw, the analysts know beforehand that the abstract discourses "coupling" and "security" do not need to be incorporated to the image bank because its characteristics are linked to technical aspects related to metallurgy/siderurgy. It is likely, however, that another photo from the image bank might have a discourse related to "security" and "coupling", when those themes mentioned some technical characteristics linked to metallurgic security or the coupling of metal bars. In that case, the discourse context is another.

When it comes to more general image banks such as those linked to news agencies, the scope of the thematic discourses might be much larger. Still, it is possible to delimitate and direct the discourses for several reasons, including: deleting photos of certain regions, of certain political or religious impressions, and photos with dates prior to the period, etc.

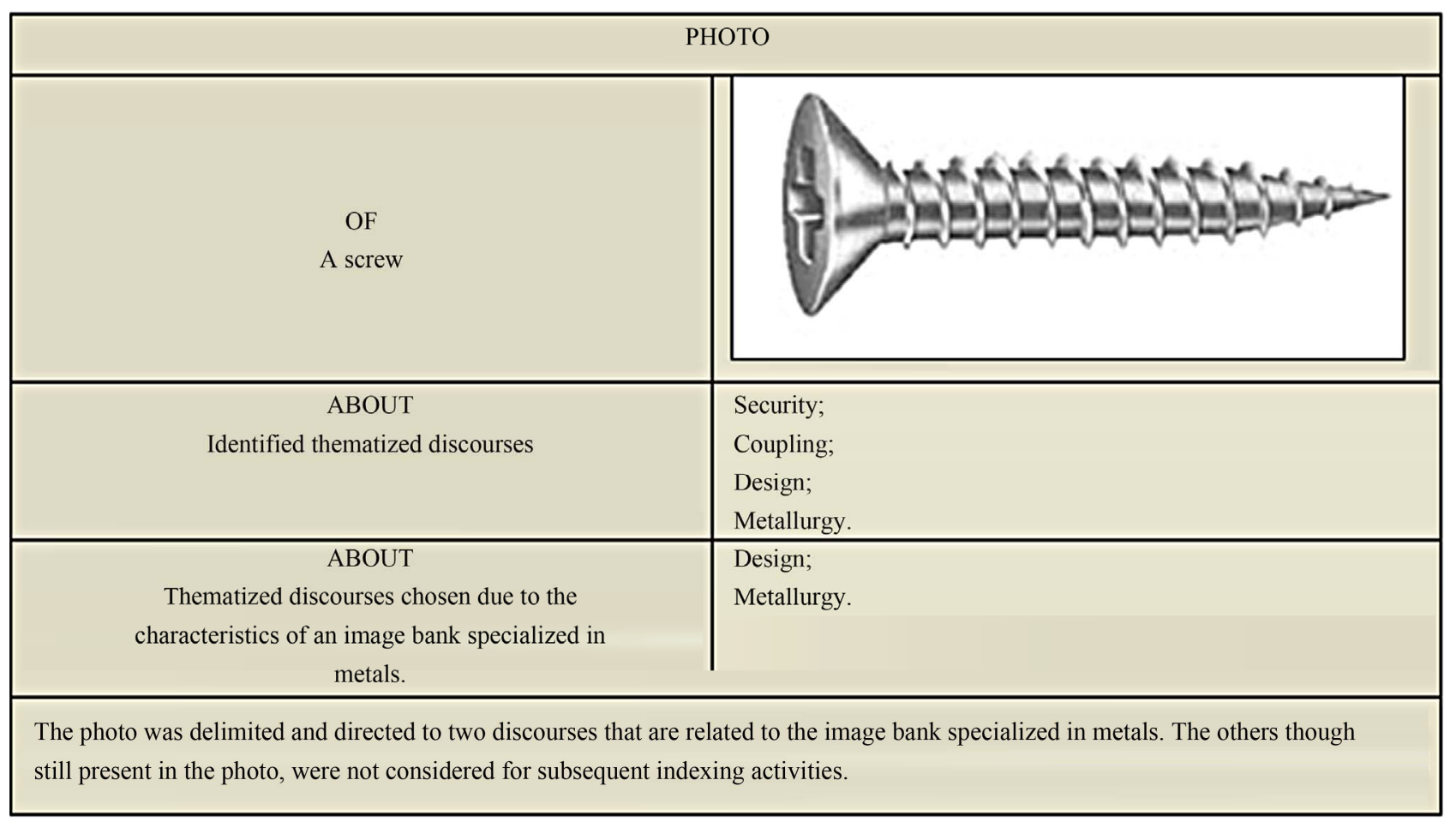

Diagrama 1. Delimitation and directing the photo of the screw's discourse. 


\section{Conclusions}

Taking into account that a photograph, devoid of a context that gives it meaning, does not exist as information; therefore, the need of determining thematized discourses before indexing is fundamentally crucial. Otherwise, the indexed data will be merely identified and descriptive indicators of a referent whatsoever. This way, the photograph will be identified by its denotative values' keywords and term descriptors. The discourses demit and direct the photo to the image bank's context, giving its meanings according to the bank's characteristics and eliminating irrelevant topics. Besides this delimitation and directing, thematization allows the grouping of photos that share one or more similar themes, although many of them are from totally different topics which, apparently, have nothing to do with each other.

In today's world, the vast proliferation of images, especially photography in the digital age, has brought with a similar problem to that of the so-called 1940s' explosion of information: the imagistic explosion. Millions of images are produced annually, and their organization in image banks is inescapable for a retrieval that meets users' needs.

As observed, photograph might have many discourses, however, they need to be delimited and directed according to their image banks' characteristics. The non-delimitation and non-directing generate the presentation of discourses that, although existing in photography, are not necessary for some image banks which store that photo. When the photograph's discourse is delimited and directed, it becomes better organized for the users' retrieval and use. Some discourses can be adopted by various image banks, while others only by some due to those banks' characteristics and objectives. Consequently, thematization limits the use of discourses that have nothing to do with a certain image bank.

\section{REFERENCES}

[1] E. Simeão and A. Miranda, "Comunicação Extensiva e a
Linguagem Plástica dos Documentos em Rede," 2007. http://eprints.rclis.org/archive/00002441/01/cextensiva.pdf

[2] R. C. Rodrigues, "Análise e Tematização da Imagem Fotográfica," IBICT, Ciência da Informação, Vol. 36, No. 3, 2007, pp. 67-76. http://dx.doi.org/10.1590/S0100-19652007000300008

[3] R. C. Rodrigues, “Análise e Tematização da Imagem Fotográfica: Determinação, Delimitação e Direcionamento dos Discursos da Imagem Fotográfica," Information Science Thesis, Universidade de Brasília, 2011.

[4] S. Sontag, "Sobre Fotografia," Cia das Letras, São Paulo, 2004.

[5] B. Kossoy, "Realidades e Ficções na Trama Fotográfica," Ateliê, São Paulo, 2002.

[6] P. Dubois, "O Ato Fotográfico e Outros Ensaios," Papirus, Campinas, 2007.

[7] S. S. Layne, "Some Issues in the Indexing of Images," Journal of the American Society for Information Science, Vol. 45, No. 8, 1994, pp. 583-584. http://dx.doi.org/10.1002/(SICI)1097-4571(199409)45:8< 583::AID-ASI13>3.0.CO;2-N

[8] Dicionário Aulete Digital. www.auletedigital.com.br

[9] Dicionario Michaelis Digital. http://michaelis.uol.com.br/

[10] J. W. Smit, "A Análise da Imagem: Um Primeiro Plano," Análise Documentária: A Análise da Síntese IBICT, Brasília, 1998.

[11] M. P. Manini, “Análise Documentária de Imagens,” 2001. http://www.ies.ufpb.br/ojs2/index.php/ies/article/view/31 $3 / 236$

[12] G. D. Maimone and L. S. Gracioso, "Representação Temática de Imagens: Perspectivas Metodológicas," UFPB, Inf. Inf., Vol. 12, No. 1, 2007.

[13] A. C. Brasil, "A Revolução das Imagens," Ciência Moderna, Rio de Janeiro, 2005.

[14] F. W. Lancaster, "Indexação e Resumos: Teoria e Prática," Briquet de Lemos, Brasília, 2004.

[15] J. A. Souza, "Indexação e Recuperação de Imagens." http://www.eps.ufsc.br/teses99/artur/cap3.htm

[16] J. G. Filho, "Gestalt do Objeto: Sistema de Leitura Visual da Forma," Escrituras, São Paulo, 2008. 